\title{
Ergonomi sebagai Upaya Pencegahan Gangguan Musculoskeletal pada Perawat
}

\author{
Rizqiyatul Laili
}

e-mail : laili.rizqiyatul@gmail.com

\section{LATAR BELAKANG}

Ergonomi adalah studi ilmiah yang mempelajari hubungan antara manusia dan tempat kerja. Prinsip utama dalam ergonomi adalah menyerasikan pekerjaan dengan pekerja atau "fitting the job to the worker". Ergonomi menyediakan desain stasiun kerja, peralatan, dan perlengkapan yang nyaman dan efisien untuk disesuaikan dengan kebutuhan pekerja. Pada akhirnya akan tercipta lingkungan kerja yang sehat, karena desain yang efektif dapat mengendalikan atau menghilangkan potensi bahaya. Cara bekerja juga diatur sedemikan rupa agar tidak terjadi ketegangan otot, kelelahan yang berlebih sehingga menyebabkan gangguan kesehatan. Namun, sangat disayangkan pada era globalisasi ini masih banyak rumah sakit yang belum menempatkan ergonomi sebagai prioritas dalam merancang lingkungan kerja, sehingga banyak tenaga kesehaktan khususnya perawat yang mengalami gangguan musculoskeletal.

Gangguan musculoskeletal disebut juga Musculoskeletal disorders (MSDs) merupakan gangguan pada sistem muskuloskeletal yang mengakibatkan gejala seperti nyeri akibat kerusakan pada nervus, dan pembuluh darah pada berbagai lokasi tubuh seperti leher, bahu, pergelangan tangan, pinggul, lutut, dan tumit disebabkan oleh cara kerja yang tidak ergonomis. Berdasarkan hal tersebut, perlu dikembangkan dan ditingkatkan upaya promosi dan preventif dalam rangka menekan serendah mungkin risiko penyakit yang timbul akibat pekerjaan atau lingkungan kerja salah satunya yakni membenahi dari sektor ergonomi untuk mencegah terjadinya gangguan musculoskeletal pada perawat sehingga dapat meningkatkan produktivitas kerja. 


\section{METODE}

Metode penelitian yang digunakan adalah literature review. Dengan melakukan analisis dan kajian bebas pada jurnal dan textbook yang sudah terjamin datanya dengan tahun 2012-2020. Pengambilan informasi melalui jurnal dan textbook adalah untuk mendapatkan berbagai informasi yang lengkap dan akurat dengan cara melakukan penyimpulan dari jurnal dan textbook tersebut. Penyimpulan yang dilakukan adalah dengan menggunakan bahasa sendiri tanpa ada meniru karya orang lain.

\section{HASIL}

Berdasarkan jurnal dan textbook tersebut, didapatkan bahwa gangguan musculoskeletal merupakan satu masalah penting dalam industri rumah sakit dan merupakan gangguan paling banyak diderita perawat. Perawat sangat berpotensi mengalami gangguan musculoskeletal di rumah sakit dikarenakan tugas yang dilakukan perawat sangat bervariasi, antara lain mengangkat dan mendorong dalam hal penanganan pasien. Penyakit akibat kerja yang umum terjadi adalah low back pain terutama diakibatkan oleh kegiatan angkat-angkut pasien, seorang perawat yang mengalami low back pain akan terganggu produktivitas kerjanya. Produktivitas kerja yang menurun pada akhirnya akan berdampak pada kualitas pelayanan pasien.

Pada aktivitas perawat yang melakukan pekerjaan mengangkat dan memindahkan pasien mempunyai tingkat risiko ergonomi sangat tinggi dan tingkat keluhan musculoskeletal disorders (MSD’s) sebesar 80\% (Kurniawidjaja dkk, 2013).

Prevalensi keluhan musculoskeletal disorders yang paling banyak ditemukan adalah pada perawat yang memiliki usia lebih tua, faktor fisik mengangkat dan mendorong pasien, posisi kerja yang tidak ergonomis dalam durasi waktu yang lama, obesitas, masa kerja yang lama, kebiasaan merokok serta kebiasaan olahraga. 


\section{PEMBAHASAN}

Muskuloskeletal Disorders (MSDs) diklasifikasikan menjadi beberapa stadium menurut Oliveira dan Browne.

a. Menurut Oliveira

1. Stadium I : Lelah, tidak nyaman, nyeri terlokalisasi yang memburuk saat bekerja dan membaik saat istirahat.

2. Stadium II : Nyeri persisten dan lebih intens, diikuti dengan parestesia dan perasaan terbakar. Memburuk saat bekerja dan aktivitas sehari-hari.

3. Stadium III : Nyeri persisten dan berat diikuti penurunan kekuatan otot dan kontrol pergerakan, edema dan parestesia.

4. Stadium IV : Nyeri kuat dan berlangsung terus menerus.

b. Menurut Browne

1. Stadium I : Nyeri saat bekerja, berhenti saat malam hari tanpa gangguan tidur.

2. Stadium II : Nyeri selama bekerja, menetap sampai malam menyebabkan gangguan tidur.

3. Stadium III : Nyeri bahkan saat beristirahat dengan gangguan tidur

Faktor risiko MSDs

Hernandez dan Peterson (2013) mengelompokkan faktor risiko dari MSDs ke dalam tiga kelompok besar yaitu faktor biomekanik, faktor psikososial, dan faktor individu.

a. Faktor biomekanik

1. Postur tubuh saat bekerja

Postur kerja yang tidak benar dapat menyebabkan posisi bagian tubuh bergerak menjauhi posisi alamiahnya, misalnya pergerakan tangan terangkat, punggung yang terlalu membungkuk, kepala terangkat, dan leher yang berputar. Semakin jauh suatu bagian tubuh seseorang dari pusat gravitasi tubuh, maka 
semakin tinggi pula risiko terjadinya keluhan sistem muskuloskeletal. Postur kerja yang tidak benar dan terlalu dipaksakan akan berdampak pada kelelahan otot sehingga kerja menjadi tidak efisien, dalam jangka waktu lama akan menyebabkan punggung.

Berdasarkan posisi tubuh, postur tubuh saat bekerja dalam ergonomi terdiri atas:

- Posisi netral adalah postur tubuh dimana setiap anggota tubuh berada pada posisi yang sesuai dengan anatomi tubuh, sehingga tidak terjadi kontraksi otot yang berlebihan serta pergeseran atau penekanan pada bagian tubuh.

- Posisi janggal adalah postur dimana posisi tubuh menyimpang secara signifikan dari posisi netral saat melakukan aktivitas yang disebabkan oleh keterabatasan tubuh dalam menghadapi beban dalam waktu lama.

Berdasarkan pergerakan, postur kerja dapat dibedakan menjadi:

- Postur statis adalah postur dimana sebagian besar tubuh tidak aktif atau hanya sedikit terjadi pergerakan. Postur statis dalam waktu lama dapat menyebabkan kontraksi otot terus menerus dan tekanan pada anggota tubuh.

- Postur Dinamis adalah postur yang terjadi dimana sebagian besar anggota tubuh bergerak. Bila pergerakan tubuh wajar, hal ini dapat membantu mencegah masalah yang ditimbulkan postur statis, namun bila terjadi pergerakan berlebihan, hal ini dapat menyebabkan masalah kesehatan.

\section{Force/beban}

Pada pekerjaan mengangkat atau mengangkut, efisiensi kerja dan pencegahan terhadap masalah tulang belakang harus mendapat perhatian cukup. Pemindahan material secara manual apabila tidak dilakukan secara ergonomis dapat menimbulkan pembebanan pada tulang punggung.

Untuk mengurangi terjadinya keluhan musculoskeletal pada perawat, maka perawat perlu diberikan pelatihan khusus tentang penanganan pasien yang ergonomis. Perawat tidak perlu berusaha untuk mengangkat pasien bila tidak 
diperlukan sekali ataupun kalau bisa diusahakan mengangkat pasien minimal dilakukan 2 orang perawat.

Frekuensi

Frekuensi merupakan banyaknya gerakan yang dilakukan dalam satu periode waktu. Jika aktivitas pekerjaan dilakukan secara berulang, maka disebut sebagai gerakan repetitif. Keluhan muskuloskeletal terjadi karena otot menerima tekanan akibat kerja terus menerus tanpa ada kesempatan untuk berelaksasi.

\section{Durasi}

Durasi adalah lamanya waktu pajanan terhadap faktor risiko. Asumsinya bahwa semakin lama durasi paparan semakin besar risiko cedera yang terjadi.23 Durasi diklasifikasikan menjadi :

- Durasi singkat : $<1$ jam/ hari

- Durasi sedang : 2 jam/hari

- Paparan Pada Getaran

Getaran akan menyebabkan bertambahnya kotraksi otot. Hal ini akan menyebabkan tidak lancarnya aliran darah, meningkatnya penimbunan asam laktat dan akhirnya timbul nyeri otot.

b. Faktor Individu

\section{Usia}

Otot memiliki kekuatan maksimal pada saat mencapai usia 20-29 tahun, lalu setelah usia mencapai 60 tahun kekuatan otot akan menurun hingga $20 \%$.

\section{Jenis kelamin}

Pada semua kelompok pekerjaan, angka prevalensi masalah muskuloskeletal lebih besar pada perempuan dibandingkan pada laki-laki. Dominasi tertinggi pada wanita ditemukan untuk pinggul dan pergelangan tangan. Hal tersebut dipengaruhi oleh faktor fisiologis kekuatan otot pada perempuan yang berkisar $2 / 3$ kekuatan otot dari pria. 


\section{Indeks Massa Tubuh (IMT)}

Keluhan MSDs yang umum terjadi pada individu yang obesitas seperti nyeri leher, tendinitis rotator cuff, osteoatritis pada lutut, nyeri kaki, dan cedera tendon Achilles terjadi disebabkan oleh ketidakseimbangan struktur rangka dalam menerima beban baik berat tubuh maupun beban dari pekerjaan.

\section{Masa Kerja}

Semakin lama waktu bekerja atau semakin lama seseorang terpapar faktor risiko maka semakin besar pula risiko untuk mengalami keluhan musculoskeletal disorders. Gejala yang timbul biasanya seperti kesemutan, perasaan terbakar, dan baal pada tangan dan jari khususnya jari telunjuk dan jari tengah.

\section{c. Faktor Psikososial}
a. Pengaruh dan kontrol pekerjaan
b. Iklim terhadap supervisor (pengawas)
c. Rangsangan dari pekerjaan itu sendiri
d. Hubungan dengan rekan kerja
e. Beban kerja secara psikologis

Gangguan Muskuloskeletal Pada Berbagai Bagian Tubuh

a. Gangguan pada tangan

1. Tendonitis: adalah peradangan pada tendon, umumnya digambarkan sebagai nyeri lokal pada titik inflamasi dan kesulitan untuk menggerakan persendian yang terkena disebabkan trauma atau penggunaan berlebih pada pergelangan tangan, siku (tennis elbow), dan sendi bahu.

2. Tenosinovitis: contohnya inflamasi kronik pada otot dan tendon pergelangan tangan bagian lateral (ibu jari). Gejala yang timbul termasuk nyeri, edema, baal, kesemutan dan sulit menggerakan ibu jari.

3. Carpal Tunnel Syndrome (CTS). CTS terjadi ketika terjadi kompresi nervus medianus pada terowongan karpal. Faktor yang menyebabkan terjadinya CTS diantaranya tekanan pada tangan dalam jangka waktu yang lama, 
pergerakan repetitif, pemakaian sarung tangan yang tidak pas, paparan tangan

4. Trigger finger atau juga dikenal sebagai tenosinovitis stenosing adalah terjadinya hentakan tiba-tiba, triggering dan terkuncinya jari pada posisi fleksi atau ekstensi.

b. Gangguan pada leher dan bahu

1. Bursitis: peradangan (pembengkakan) atau iritasi yang terjadi pada jaringan ikat yang berada pada sekitar persendian. Penyakit ini akibat posisi bahu yang janggal seperti mengangkat bahu di atas kepala dan bekerja dalam waktu yang lama.

2. Tension Neck Syndrome: gejala ini terjadi pada leher yang mengalami ketegangan pada otot-ototnya disebabkan postur leher menengadah ke atas dalam waktu yang lama. Sindroma ini mengakibatkan kekakuan pada otot leher, kejang otot, dan rasa sakit yang menyebar ke bagian leher.

3. Thoracic Outlet Syndrome: adalah terjadinya kompresi pada pleksus brachialis, arteri dan vena subclavialis pada ekstremitas atas. Gejala yang timbul antara lain, nyeri pada bahu atau lengan, baal dan kesemutan pada jari.

c. Gangguan pada punggung dan lutut

1. Low Back Pain: kondisi patologis yang mempengaruhi tulang, tendon, syaraf, ligamen, intervertebral disc dari lumbar spine (tulang belakang). Cidera pada punggung dikarenakan otot-otot tulang belakang mengalami peregangan jika postur punggung sering membungkuk. Diskus mengalami tekanan yang kuat dan menekan juga bagian dari tulang belakang termasuk syaraf.

2. Pada lutut Penyakit muskuloskeletal yang terdapat di bagian lutut berkaitan dengan tekanan pada cairan di antara tulang dan tendon. Tekanan yang berlangsung terus menerus akan mengakibatkan cairan tersebut (bursa) tertekan, membengkak, kaku, dan meradang atau biasa disebut bursitis. 
Tekanan dari luar ini juga menyebabkan tendon pada lutut meradang yang akhirnya menyebabkan sakit (tendinitis).

d. Gangguan muskuloskeletal pada kaki atau tumit (Ankle strains / sprains).

Ankle strains terjadi akibat tertariknya tendon dari otot. Sedangkan sprain diakibatkan terjadi peregegangan atau robeknya ligament pada sistem muskuloskeletal. Gejala yang mungkin timbul seperti nyeri, bengkak, merah, dan kesulitan untuk menggerakan persendian.

Aplikasi Ergonomi

\section{Kerja Duduk}

Ditinjau dari aspek kesehatan, bekerja dengan posisi duduk yang memerlukan waktu lama dapat menimbulkan otot perut semakin elastis, tulang belakang melengkung, otot bagian mata terkonsentrasi sehingga cepat merasa lelah.

Hal-hal yang harus diperhatikan dalam melaksanakan pekerjaan dengan duduk:

a. Duduk bergantian dengan berdiri dan berjalan, duduk dalam waktu yang relatif lama harus dihindari karena akan berpengaruh pada kesehatan.

b. Ketinggian kursi dan sandaran kursi harus disesuaikan, ketinggian kursi harus dipilih sedemikian rupa sehingga ketika duduk, bagian belakang lutut tidak sempit. Sandaran harus memberikan kenyamanan terutama untuk punggung bagian bawah.

c. Karakteristik kursi secara spesifik ditentukan oleh jenis tugas, sebuah kursi dengan sandaran lengan dapat dipilih jika dipandang tidak mengahambat kegiatan.

d. Ketinggian bekerja bergantung pada tugas

e. Gunakan sandaran kaki jika tinggi pekerjaan tetap. Jika ketinggian kerja tidak dapat disesuaikan oleh pengguna, seperti pada mesin, permukaan kerja yang relative tinggi harus dipilih sesuai dengan tinggi pengguna.

f. Hindari jangkauan berlebihan, benda kerja, alat, dan kontrol yang digunakan secara teratur harus ditempatkan di depan atau di dekat tubuh. 


\section{Kerja Berdiri}

Postur tubuh dalam pekerjaan berdiri merupakan suatu totalitas perilaku kesiagaan dalam menjaga keseimbangan fisik dan mental.

Hal-hal yang harus diperhatikan dalam posisi kerja berdiri:

a. Berdiri bergantian dengan duduk dan berjalan. Tugas yang harus dilakukan dalam waktu lama dengan posisi berdiri harus diselingi dengan tugas yang dapat dilakukan dengan duduk dan berjalan.

b. Ketinggian meja kerja harus disesuaikan. Ketinggian meja kerja harus disesuaikan dengan jenis pekerjaan.

c. Menyediakan cukup ruang untuk kaki. Antara bagian tengah meja harus lebih lebar $5 \mathrm{~cm}$ dengan tumpuan meja. Antara sandaran meja dan jarak lantai minimal $75 \mathrm{~cm}$.

d. Hindari jangkauan berlebihan. benda kerja, alat, dan kontrol yang digunakan secara teratur harus ditempatkan di depan atau di dekat tubuh.

e. Pilih permukaan kerja yang miring untuk membaca tugas.

f. Postur tangan dan lengan. Bekerja untuk jangka waktu yang lama dengan tangan dan lengan dalam sikap tubuh yang buruk dapat menyebabkan keluhan spesifik dari pergelangan tangan, siku, dan bahu. Masalah ini timbul terutama dari manual handling alat.

g. Pilih model alat yang tepat. Sebuah alat tertentu sering tersedia dalam berbagai model. Pilih model yang paling cocok untuk tugas dan postur tubuh agar tidak terjadi permasalahan di persendian.

h. Bila menggunakan alat genggam, pergelangan tangan harus dijaga selurus mungkin. Alat genggam tidak boleh terlalu berat. Alat genggam yang masih bisa ditoleransi beratnya adalah sekitar $2 \mathrm{~kg}$.

i. Perawatan alat. Alat kerja harus dijaga kualitasnya agar tidak membutuhkan kekuatan yang besar dalam penggunaannya.

j. Hindari melaksanakan tugas di atas bahu. Jika pekerjaan di atas permukaan bahu tidak dapat dihindari, durasi kerja harus terbatas dengan diselingi oleh istirahat teratur. 
3. Manual material handling (MMH)

Manual material handling adalah aktivitas penanganan material yang meliputi kegiatan mengangkat, menurunkan, mendorong, menarik, memutar, menahan dan membawa beban yang dilakukan tanpa bantuan alat.

Untuk mencegah masalah kesehatan maupun cidera akibat manual material handling, beberapa pemindahan material secara teknis dapat dilakukan dengan cara sebagai berikut :

Ada beberapa cara mengangkat beban yang benar, yaitu :

1. Memegang dan mengangkat beban

- Dengan posisi tubuh setegak mungkin

- Dengan posisi punggung lurus

- Dengan posisi lutut cenderung kuat

2. Taruhlah beban sedekat mungkin dengan tubuh anda.

3. Memegang beban dengan cara yang aman (pada handle) sehingga anda dapat melakukan pemindahan dengan sekuat mungkin.

4. Perlu didesain alat bantu agar mengurangi aktifitas membungkuk untuk mengambil dan memindahkan barang.

\section{PENUTUP}

Ergonomi merupakan hal yang sangat penting dalam dunia kesehatan, namun masih perlu didorong implementasinya oleh berbagai pihak. Dampak positif yang dapat diperoleh dengan penerapan prinsip ergonomi bukan hanya kenyamanan dan keamanan yang dirasakan perawat, namun juga dapat mencegah terjadinya gangguan musculoskeletal akibat kerja dan dapat meningkatkan produktivitas kerja. 


\section{DAFTAR PUSTAKA}

Mayasari, D., Saftarina, F., 2016, Ergonomi sebagai Upaya Pencegahan Musculoskeletal Disorders pada Pekerja. Jurnal Kedokteran Unila Vol. 1 No. 2.

Sulistiyo T.H., Rico J. Sitorus , Ngudiantoro, 2018, Analisis faktor risiko ergonomi dan musculoskeletal disorders pada radiografer instalasi radiologi rumah sakit di kota Palembang. JKK, Vol. 5, No 1, 26-37.

Padmanathan V, Joseph L, Omar B, dan Nawawi R. Prevalence Of Musculoskeletal Disorders And Related Occupational Causative Factors Among Electricity Linemen : A Narrative Review. IJOMEH. 2016;29(5):725-34

Balaputra, I.,\& Sutomo, A.H., 2017, Pengetahuan ergonomi dan postur kerja perawat pada perawatan luka dengan gangguan muskuloskeletal di dr. H. Koesnadi Bondowoso Berita Kedokteran Masyarakat, Vol. 33 No. 9

As'adi, A. Musthofa. Sujoso, A. Prahastuti., Prasetyowati, I., 2014. Hubungan Antara Karakteristik Individu Dan Manual Material Handling Dengan Keluhan Muskuloskeletal Akibat Kerja. EJurnal Pustaka Kesehatan. Vol. 2 (No.2).

Putri, S.E., Suwandi, T., Makomulamin, 2018, HUBUNGAN ANGKAT ANGKUT PASIEN DENGAN KELUHAN MUSCULOSKELETAL DISORDERS (MSD'S) PADA PERAWAT RUANG RAWAT INAP RSUD TELUK KUANTAN TAHUN 2018, Jurnal Photon Vol. 9. No. 1.

Permata, E. G., Husni, A, 2016. Analisis Gangguan Muskuloskeletal Terhadap Perawat Berdasarkan Tingkat Paparan dengan Menggunakan Metode Movement and Assistance of Hospital Patients (mapo) Index. Jurnal Teknik Industri Vol. 2, No. 1

Helmina , Noor Diani, Ifa Hafifah, 2019. HUBUNGAN UMUR, JENIS KELAMIN, MASA KERJA DAN KEBIASAAN OLAHRAGA DENGAN KELUHAN MUSCULOSKELETAL DISORDERS (MSDs) PADA PERAWAT, Caring Nursing Jurnal Vol. 3 No. 1 
Suzana Indragiri, Triesda Yuttya, 2018. MANAJEMEN RISIKO K3 MENGGUNAKAN HAZARD IDENTIFICATION RISK ASSESSMENT AND RISK CONTROL (HIRARC) JURNAL KESEHATAN. Vol. 9 No. 1

Novie E. Mauliku, 2011. Kajian analisis penerapan sistem manajemen K3RS di Rumah Sakit Immanuel Bandung. Bandung: Jurnal Kesehatan Kartika. Stikes A. Yani Cimahi

Simamora, R. H. (2020). Learning of Patient Identification in Patient Safety Programs Through Clinical Preceptor Models. Medico Legal Update, 20(3), 553556.

Fathi, A., \& Simamora, R. H. (2019, March). Investigating nurses' coping strategies in their workplace as an indicator of quality of nurses' life in Indonesia: a preliminary study. In IOP conference series: Earth and Environmental science (Vol. 248, No. 1, p. 012031). IOP Publishing. 